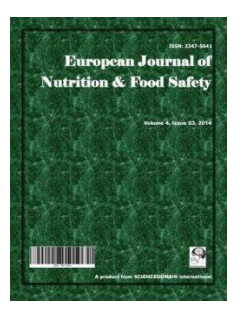

\title{
Relationship between Prolonged Sweetener Consumption and Chronic Stress in the Production of Carbonylated Proteins in Blood Lymphocytes
}

\author{
Lucía García-Iniesta ${ }^{1}$, Beatriz E. Martínez-Carrillo ${ }^{1 *}$, Roxana Valdés-Ramos ${ }^{1}$, \\ Rosa A. Jarillo-Luna ${ }^{2}$, Jorge A. Escoto-Herrera ${ }^{1}$ and Aldo Reséndiz-Albor ${ }^{2}$ \\ ${ }^{1}$ Laboratorio de Investigación en Nutrición, Facultad de Medicina, Universidad Autónoma del Estado \\ de México, Paseo Tollocan esquina Jesús Carranza s/n, Colonia Moderna de la Cruz, C.P. 50180, \\ Toluca, MEX., México. \\ ${ }^{2}$ Sección de Posgrado e Investigación, Escuela Superior de Medicina, Instituto Politécnico Nacional, \\ Plan de San Luis y Díaz Mirón 11340, Ciudad de México, DF, México.
}

Authors' contributions

This work was carried out in collaboration between all authors. Authors BEMC, LGI and RAJL designed the study, performed the statistical analysis, wrote the protocol and wrote the first draft of the manuscript. Authors RVR and JAEH managed the analyses of the study. Author ARA managed the literature searches. All authors read and approved the final manuscript.

Article Information

DOI: $10.9734 / E J N F S / 2017 / 36313$

Original Research Article

Received $23^{\text {rd }}$ August 2017 Accepted $10^{\text {th }}$ October 2017 Published $16^{\text {th }}$ October 2017

\section{ABSTRACT}

Introduction: Modern lifestyles have changed eating habits, encouraged physical inactivity, and increased stress in daily life. These living conditions cause elevated concentrations of carbonylated proteins like biomarker of oxidative stress. The expression of this proteins represent irreversible damage to structural intracellular proteins in cells and extracellular matrix. It is not clear whether a rise in the concentration of these proteins is the origin or consequence of diseases.

Objective: To determine in a healthy young mice model the possible correlation between prolonged sweetener consumption and the presence of chronic physiological stress, evidenced by the production of carbonylated proteins in peripheral blood lymphocytes.

Methods: Sixty-four 21-day-old CD1 male mice were divided into two groups, stressed (with immobilization) and unstressed. Each group was divided into four subgroups: Control or experimental with a 6-week administration of sucrose, sucralose or stevia. Body mass index, food intake, number and concentration of carbonylated proteins, levels of glucose and peripheral lymphocytes in blood were evaluated. Data were analyzed with ANOVA.

Results: Compared to the unstressed control, the glucose concentration was elevated in all 
stressed subgroups $(F=13.41, p<0.01)$, with greater weight found in the stressed sucralose supplemented subgroup $(F=77.58, p<0.001)$. The blood level of peripheral lymphocytes was above the control in all subgroups $(F=19.97, p<0.01)$, except the decrease observed in unstressed sucrose supplemented subgroup. Carbonylated protein concentration in peripheral blood lymphocytes was high in all subgroups (versus the control) except in unstressed animals suppelemented with stevia $(F=51.16, p<0.01)$.

Conclusions: Stress plus sucralose increased number of lymphocytes and carbonylated proteins concentration. The physiological stress with or without sweetener consumption generated increase in carbonylated proteins concentration. Stevia did not modify lymphocytes and carbonylated proteins.

Keywords: Sweetener; stress; lymphocytes; carbonylated proteins.

\section{ABBREVIATIONS}

$\begin{array}{ll}\text { ROS } & \text { : Reactive Oxygen Species } \\ \text { WS } & \text { : Without Stress } \\ \text { S } & : \text { Stressed } \\ \text { CL } & : \text { Control } \\ \text { Suc } & : \text { Sucrose } \\ \text { Sucl } & : \text { Sucralose } \\ \text { St } & : \text { Stevia } \\ \text { S } & \text { : Stress } \\ \text { BMI } & : \text { Body Mass Index }\end{array}$

\section{INTRODUCTION}

Sweeteners are substances that cause a sweet taste and psychobiologically stimulate human beings. This sweetness is pleasant and promotes an excessive intake of foods rich in simple carbohydrates $[1,2]$. Sweeteners can be nutritive or non-nutritive. Sucrose (sugar) is widely used as a natural and nutritive sweetener. It is extracted from the root of beets or sugarcane and provides $4 \mathrm{kcal}$ per gram [3]. Non-nutritive sweeteners have been sought as an alternative source of sweet taste. Currently, the most commonly consumed sweeteners are sucralose and stevia [4]. Sucralose, commercially known as Splenda $^{\circledR}$, is an artificial sweetener [5] produced by the selective halogenation of sucrose, where the three hydroxyl groups are replaced by chlorine [6]. Steviol glycosides are natural sweeteners derived from the purification of Stevia Rebaudiana Bertoni, also known as "honey leaf" due to its strong sweetening effect [7]. Each of these sweeteners is metabolized differently. Sucrose is hydrolyzed in the intestine to two monosaccharides, glucose and fructose, which are transported through the apical membrane of the intestinal epithelial cells by facilitated transport (GLUT5) and then pass through the basolateral membrane into the blood flow (GLUT2) [8,9]. Unlike sucrose, sucralose is not utilized in the body as an energy substrate because it is not recognized as a carbohydrate.
About $2 \%$ of the ingested sucralose is bio transformed into negligible toxic components that are excreted in the urine [10]. Steviol glycosides are hydrolyzed by the intestinal microbiota to steviol metabolites, which are absorbed in the form of steviol. This is transformed in the liver to steviol glucuronide and eliminated through feces [11].

Since sucrose consumption has been associated with diseases, such as dental caries, diabetes mellitus, cancer and obesity, a decrease in its dietary content has been recommended [12]. Although the repercussions of sucralose in the diet are still controversial, recent studies suggest adverse effects on glucose tolerance resulting from an alteration of the intestinal microbiota $[5,13,14]$. On the other hand, stevia (like sucrose) is more clearly correlated with disease. Whereas the crude extracts of the stevia leaf are linked to infertility, kidney and cardiovascular damage [15], the pure extracts are related to anti-inflammatory, immunomodulatory and antiapoptotic activity [16].

Controversy exists about the secondary effects on the immune system caused by the consumption of these sweeteners. Sucrose intake is related to increased concentrations of inflammatory markers such as haptoglobin, transferrin and C-reactive protein [17]. Sucralose suppresses the secretion of interleukin (IL)- 6 and IL-10 [18] and modifies the composition of the intestinal microbiota and other immune pathologies [5]. The immunomodulatory activity of stevia is attributed to the stimulation of cellular and humoral immunity, and $B$ and $T$ cell proliferation [19].

Nowadays, people are living under physiological stress from multiple sources, including emotional and psychological stress situations (e.g., from work and financial pressures) as well as physical factors in the environment. Stress is defined as a 
state of dissonance or threat to homeostasis that elicits a response in the organism, which in turn interacts with the environment. This response is related to previous experiences and other factors unique to each individual [20]. Exposure to prolonged stress has physiological and psychological consequences for an individual [21,22], such as hyperglycemia, neuronal cell death and immunosuppression [23]. Additionally, stress contributes to the excessive production of reactive oxygen species (ROS) under certain exogenous conditions, including excessive use of alcohol [24], environmental pollution [25] and other stressful situations physics, psychologic and organic [26].

One exogenous factor that may engender excessive carbonylated proteins is an exaggerated level of sweeteners in the diet. There are no studies, to our knowledge, on the possible relation between the consumption of non-nutritive sweeteners and the presence of physiological stress or oxidative stress in blood lymphocytes. It has been demonstrated that chronic hyperglycemia favors the development of oxidative stress and inflammation. Chronic stress has been related to the presence of oxidative stress in liver, kidney, heart, lungs and brain [27]. Most studies evaluating carbonylated protein concentrations have done so by analyzing biological samples of humans under pathological conditions, including the plasma of children with juvenile rheumatoid arthritis and tracheal aspirates of premature infants with mechanical ventilation. Other conditions studied have been severe sepsis, trauma and acute pancreatitis, mild cognitive impairment, and recently diagnosed and non-complicated diabetes; these studies suggest that the increase in oxidative stress may not result from the complications of these diseases, but instead could be a contributor to their development. All these reports dealt with diseases at an advanced stage of inflammation [28]. Studies evaluating the impact of non-nutritive sweeteners on oxidative stress in healthy subjects are scarce. A biomarker that reflects the damage caused by an excessive production of ROS is the carbonylation of proteins, characterized by a non-enzymatic and irreversible reaction having adverse effects on cells, which results from a change in the structure and function of proteins [27,29]. Therefore, the aim of the present study was to examine the possible correlation between the prolonged consumption of sweeteners and oxidative stress in a model of healthy young mice with chronic physiological stress. The parameter employed for measuring oxidative stress was the concentration of carbonylated proteins in peripheral blood lymphocytes.

\section{MATERIALS AND METHODS}

\subsection{Animals}

This was an experimental, prospective, controlled and randomized study. Weanling 21day-old male CD1 mice were obtained from the bioterium of the Faculty of Medicine, Universidad Autónoma del Estado de México. Animal care and experimental procedures were carried out in accordance with the standards of the Research Ethics Committee of Faculty of Medicine and International Regulation for the Use of Laboratory Animals, the norms of the Universidad Autónoma del Estado de México, and the guidelines of the Mexican Ministry of Health for the production and Care of Laboratory Animals (NOM-062-ZOO-1999 Ministry of Agriculture, Mexico City, Mexico). Animals were housed in individual cages throughout the experiment with temperature controlled $\left(21 \pm 1^{\circ} \mathrm{C}\right)$ and maintained on a 12/12 h light/dark cycle. A normal diet (Rodent Laboratory Chow 5001 Purina, $3.02 \mathrm{Kcal} / \mathrm{gr}$ ) and water were provided ad libitum from the $4^{\text {th }}$ to the $9^{\text {th }}$ week of life.

\subsection{Experimental Groups}

Mice were randomly assigned to one of two experimental groups (in each case, $n=32$ ): i) Without stress (WS) and ii) stressed (S). For sweetener administration, each group was divided into four subgroups. The WS subgroups were: a) Control (CL), b) Sucrose (Suc), c) Sucralose (Sucl), and d) Stevia (St). The $S$ subgroups were: a) Control + Stress $(\mathrm{CL}+\mathrm{S})$, b) Sucrose + Stress (Suc + S), c) Sucralose + Stress $($ Sucl + S), and d) Stevia + Stress (St + $\mathrm{S})$. The treatments were administered for 6 weeks (during the $4^{\text {th }}$ to $9^{\text {th }}$ week of animal life). At the end of the $6^{\text {th }}$ week of treatment, glucose concentration $(\mathrm{mg} / \mathrm{dL})$, weight gain $(\mathrm{g})$, body mass index (BMI), and food and water consumption were quantified and measured weekly.

\subsection{Sweetener Administration}

The solution containing a sweetener was prepared with ultrapure water and administered at a concentration of $41 \mathrm{mg} / \mathrm{ml} / \mathrm{g}$ of weight/week (Suc), and $4.1 \mathrm{mg} / \mathrm{ml} / \mathrm{g}$ of weight/week (Sucl and 
St). This according to the recommendations of Official Mexican Standard NOM-218-SSA1-2011 from non-alcoholic flavored drinks. The sweeteners were administered in the morning $(8$ at $10 \mathrm{am})$ by direct oral deposition $(500 \mu \mathrm{l})$ with a graduated pipette.

\subsection{Stress Model}

An immobilization model was used for inducing stress. Mice were introduced into an acrylic tube, suitable in size and ventilation, fixing the tail of the mouse to the outer surface with adhesive tape. Exposure to stress was performed daily for $2 \mathrm{~h}(10-12 \mathrm{pm})$ for 5 days a week (Monday through Friday) $[25,26]$.

\subsection{Quantification of the Body Mass Index (BMI)}

The BMI of animals was calculated at the end of 6 weeks of treatment (on the $9^{\text {th }}$ week of animal life) with the formula $\mathrm{BMI}=$ mass $(\mathrm{g}) /$ length $(\mathrm{cm})^{2}$. Length was measured from the nose to anus of the animals [30,31].

\subsection{Quantification of Glucose}

The concentration of glucose was determined in peripheral blood at the end of the $6^{\text {th }}$ week of treatments. Blood samples were obtained by puncturing the distal portion of the tail and using a One Touch Bayer glucometer, after sweetener administration and stress exposure.

\subsection{Collection of Biological Samples}

At the end of the $9^{\text {th }}$ week of life, the animals were anaesthetized with pentobarbital (80 $\mathrm{mg} / \mathrm{kg}$ ), bled by direct cardiac puncture (using a syringe with heparin), and sacrificed by cervical dislocation. From the blood samples, lymphocytes were purified utilizing FicollHypaque Plus (GE Healthcare Bio-Sciences AB, Sweden). Cells were maintained in a cold RPMI1640 medium (Sigma-Aldrich, USA), then centrifuged at $2500 \mathrm{rpm}$ for $5 \mathrm{~min}$. The button of blood cells obtained was placed in a hypotonic buffer solution $\left(8.26 \mathrm{~g} / \mathrm{L}\right.$ of $\mathrm{NH}_{4} \mathrm{Cl}, 1 \mathrm{~g} / \mathrm{L}$ of $\mathrm{KHCO}_{3}$ and $0.037 \mathrm{~g} / \mathrm{L}$ of EDTA-4Na, pH 7.4) to lyse erythrocytes. The single-cell suspension of blood was washed with PBS. Cell viability was assessed with a trypan blue assay and counted in a Neubauer chamber. To determine the number of lymphocytes, the cell button was suspended in $1 \mathrm{~mL}$ of PBS. The cell count was performed by placing $50 \mu \mathrm{l}$ of the suspension in the Neubauer chamber. Cells were counted in 4 corners (large squares) of the Neubauer chamber. The number of cells counted is reported as number of cells per $10^{3}$ cells $/ \mathrm{mL}$ volume.

\subsection{Determination of Carbonylated Proteins}

Protein carbonyl groups were detected and quantified with 2,4-dinitrophenylhydrazine (DNPH) [32]. Briefly, $0.5 \mathrm{~mL}$ serum (1 mg protein $/ \mathrm{mL}$ ) were treated with $0.5 \mathrm{~mL} 10 \mathrm{mM}$ DNPH in $2 \mathrm{M} \mathrm{HCL}$, or with $0.5 \mathrm{~mL} 2 \mathrm{M} \mathrm{HCL}$ alone for the blank. Samples were incubated for $1 \mathrm{~h}$ at room temperature in the dark and then treated with 10\% trichloroacetic acid and centrifuged. The pellet was washed three times in ethanol/ethyl acetate and solubilized in $1 \mathrm{~mL}$ of 6 $\mathrm{M}$ guanidine with $20 \mathrm{mM}$ potassium phosphate, adjusted to $\mathrm{pH} 2.3$ with trifluoroacetic acid. The resulting solution was incubated at $37^{\circ} \mathrm{C}$ for 15 min. Carbonylated protein concentration was calculated from the difference in absorbance at $370 \mathrm{~nm}$ between DNPH-treated and HCL-treated samples, with $\varepsilon 370=22,000 \mathrm{~m}^{-1} \mathrm{~cm}^{-1}$. The carbonyl content was expressed as nanomoles of carbonyl per milligram of protein.

\subsection{Statistical Analysis}

Data are expressed as the mean \pm SD. Comparisons between subgroups were performed with one-way ANOVA, and those between the WS and $S$ groups were done with two-way ANOVA. If a significant main effect or association was identified, the means of the respective groups were compared by using the Bonferroni $t$-test. In all cases, a $p$-value $<0.05$ was considered significant. All analyses were carried out with SPSS software 20.0, as was the creation of graphics (SPSS Inc.).

\section{RESULTS AND DISCUSSION}

\subsection{Results}

\subsubsection{Stress and sweetener consumption} modified the Body Mass Index (BMI)

At the end of the $6^{\text {th }}$ week of treatment, no significant differences existed in the group without stress (WS) $(F=1.05, p=0.385)$. On the other hand, in the stressed group (S) a significant difference was present $(\mathrm{F}=71.55, \quad p<0.001)$ between the control $(\mathrm{CL}+\mathrm{S})$ and all other 
subgroups (Table 1): Suc $+S(p<0.001)$, Sucl + $S(p<0.005)$ and $S t+S(p<0.002)$. Significant differences were found between the two groups, stressed and unstressed $(F=19.27, p<0.001)$. In relation to the $\mathrm{CL}$, BMI was lower in the Suc $+\mathrm{S}$ subgroup $(p<0.031)$ and higher in the Sucl $+S$ subgroup $(p<0.001)$. Compared to the $\mathrm{CL}+\mathrm{S}$, the Suc $(p<0.010)$ and St $(p<0.001)$ subgroups had a lower BMI. When analyzing the stressed and unstressed Sucl and St subgroups, a greater increase in BMI was observed for animals with administration of sucralose (Table 1).

\subsubsection{Stress decreased the weight of mice}

After the 6-week treatment period, unstressed mice showed no significant differences in weight between the $C L$ and any subgroup $(F=1.19$, $p=0.32$; Table 1). Compared to the control without stress, the stressed group $(\mathrm{CL}+\mathrm{S})$, contrarily, a significantly reduced weight $(F=77.58, p<0.001)$ was detected in the sucrose and stevia subgroups of $(p<0.001$ and 0.007 , respectively). The comparison of the stressed and unstressed groups showed a significant difference between the two $(\mathrm{F}=23.52, p<0.001)$. Compared to the $\mathrm{CL}$, there was a weight decrease in the Suc $+S$ subgroup $(p<0.001)$ and an increase in the Sucl $+S$ subgroup $(p<0.005)$. The weight of animals in the unstressed subgroups (Suc, Sucl and St) was significantly lower than the $C L+S$ control $(p<0.001$; Table 1$)$.

\subsubsection{Glucose concentration increased with stress, independently of sweetener consumption}

The concentration of glucose was higher $(F=3.46, \quad p=0.029)$ in the unstressed Suc subgroup $(p=0.047)$ versus the corresponding control at the end of the $6^{\text {th }}$ week of treatment, but no differences were found in this parameter between stressed subgroups $(\mathrm{F}=2.05, p=0.12)$. There were differences in glucose concentration between the stressed and unstressed groups $(F=13.41, \quad p<0.001)$. In relation to the $C L$, glucose concentrations were elevated in Suc + $\mathrm{S}$, Sucl $+\mathrm{S}$ and $\mathrm{St}+\mathrm{S}$ subgroups $(p<0.001$; Fig. $1)$. The St subgroup did not show a significant difference with the $C L$, but the increase was clear with the $S t+S$ subgroup.

\subsubsection{Both groups with sucralose administration had lower food intake}

In both the WS and $S$ groups, there was a significant difference in food intake when comparing the subgroups to their respective control $(F=636.48, p<0.001)$ at the end of the $6^{\text {th }}$ week of treatment. Reduced food intake was found in both the Sucl and Sucl $+S$ subgroups $(p<0.001$ in each case), while increased food consumption was detected in the St and $\mathrm{St}+\mathrm{S}$ subgroups $(p<0.011$ and $p<0.001$, respectively; Table 1). When comparing the stressed and unstressed groups, the former showed reduced food intake (Table 1) in three subgroups $(C L+S$, Suc $+S$ and Sucl $+S, p<0.001$, respectively), but not in $S t+S(p=1.00)$.

\subsubsection{Sucralose diminished the percentage of peripheral blood lymphocytes in the unstressed group}

A decreased percentage of lymphocytes was observed in the Sucl $(p<0.001)$ subgroup compared with the $\mathrm{CL}(\mathrm{F}=7.12, p<0.001)$ at the end of the $6^{\text {th }}$ week of treatment. No significant differences existed in the percentage of peripheral blood lymphocytes in the $S$ group $(\mathrm{F}=2.93, p<0.051$; Fig. 2). A lower percentage of lymphocytes was found in the unstressed than stressed group $(\mathrm{F}=52.83, p<0.001)$. In relation to the $\mathrm{CL}+\mathrm{S}$, there was a reduced percentage of peripheral blood lymphocytes in the unstressed subgroups (Suc, $p<0.001$; Sucl, $p<0.001$; St, $p<0.001)$. Compared to the $C L$, in contrast, there was a higher percentage of peripheral blood lymphocytes in the stressed group, but without differences between subgroups (Suc $+S$, $p=1.00$; Sucl + S, $p<0.16$; St $+\mathrm{S}, p<1.00$; Fig. 2).

\subsubsection{Carbonylated protein concentration in peripheral blood lymphocytes was increased with sucralose but diminished with stevia}

In the unstressed group, the carbonylated protein concentration was significantly higher $(F=188.41$, $p<0.001)$ in blood lymphocytes of the Suc $(p<0.001)$ and Sucl $(p<0.001)$ subgroups compared to the $C L$ at the end of the $6^{\text {th }}$ week of treatment, but showed values similar to this control in the St Subgroup ( $p=1.00$; Fig. 3). In the stressed group, carbonylated protein concentration was elevated $(\mathrm{F}=21.42, p<0.001)$ in all sweetener subgroups (Suc $+S, p=0.034$; Sucl $+S, p<0.001 ; S t+S, p<0.004)$ compared to the $\mathrm{CL}+\mathrm{S}$. An increase in carbonylated protein concentration was observed in five subgroups $(F=80.47, p<0.001)$ versus the corresponding control ( $p<0.001$ in all cases). The only exception was the St subgroup, which did not show a significant difference in relation to the CL (Fig. 3). 
Table 1. Effect of sweetener consumption and physiological stress on morphometric values and food intake

\begin{tabular}{|c|c|c|c|c|c|c|c|c|}
\hline \multirow[t]{2}{*}{ Subgroups } & \multicolumn{4}{|c|}{ Without stress } & \multicolumn{4}{|c|}{ Stressed } \\
\hline & $\begin{array}{l}C L \\
n=8\end{array}$ & $\begin{array}{l}\text { Suc } \\
n=8\end{array}$ & $\begin{array}{l}\text { Sucl } \\
n=8\end{array}$ & $\begin{array}{l}\text { St } \\
n=8\end{array}$ & $\begin{array}{l}C L+S \\
n=8\end{array}$ & $\begin{array}{l}\text { Suc }+S \\
n=8\end{array}$ & $\begin{array}{l}\text { Sucl + S } \\
n=8\end{array}$ & $\begin{array}{l}S t+S \\
n=8\end{array}$ \\
\hline \multicolumn{9}{|l|}{$\begin{array}{l}\text { 6-week } \\
\text { treatment }\end{array}$} \\
\hline Weight (gr) & 35.0 & $34.9 \pm 1.9$ & $35.5 \pm 2.9$ & $33.5 \pm 2.1$ & $38.8 \pm 0.7$ & $29.5 \pm 1^{*}$ & $40.3 \pm 2.0$ & $35.0 \pm 1^{*}$ \\
\hline$+\mathrm{BMI}\left(\mathrm{gr} / \mathrm{cm}^{2}\right)$ & $28.7 \pm 2$ & $27.6 \pm 3$ & $29 \pm 2.4$ & $26.9 \pm 2.4$ & $31.9 \pm 1$ & $24.9 \pm 1^{*}$ & $36 \pm 1^{*}$ & $28.6 \pm 2^{*}$ \\
\hline $\begin{array}{l}\text { Food intake } \\
\text { (g/week) }\end{array}$ & $54.4 \pm 1$ & $48.2 \pm 1$ & $26.0 \pm 1^{*}$ & $58.9 \pm 2^{*}$ & $66.2 \pm 1$ & $64.2 \pm 1$ & $46.8 \pm 1^{*}$ & $73.9 \pm 1^{*}$ \\
\hline
\end{tabular}

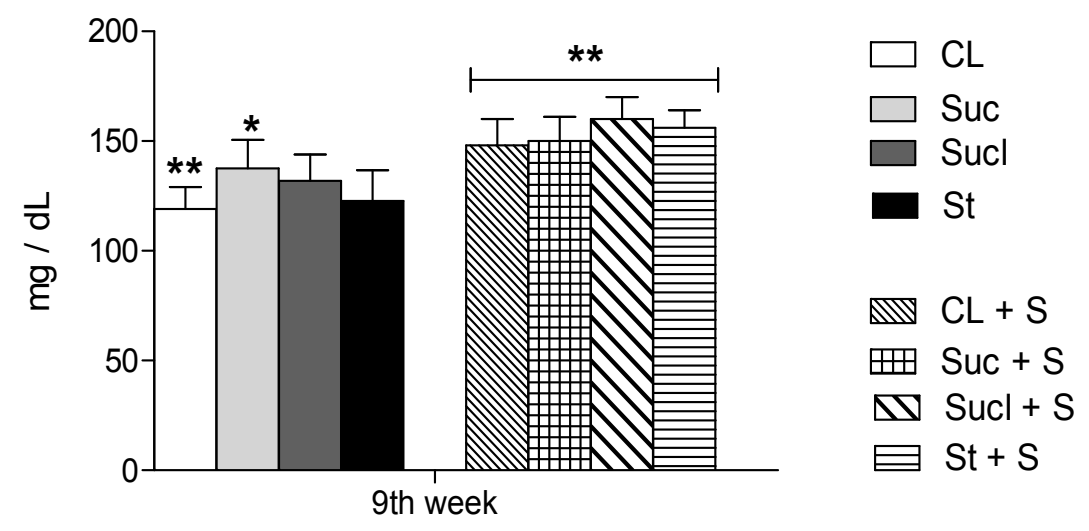

Fig. 1. Glucose concentration in CD1 mice, stressed and unstressed, with administration of sweeteners for 6 weeks

Glucose concentration was increased in all groups subjected to immobilization stress. The figure shows that the subgroup of Sucralose without stress increased the concentration of glucose in peripheral blood. The consumption of Sucralose increases the glucose in peripheral blood. Values represent the mean $\pm S D$ of each group: CL (Control), Suc (Sucrose), Sucl (Sucralose), St (Stevia), CL + S (Control + Stress), Suc + S (Sucrose + Stress), Sucl + S (Sucralose + Stress), and St + S (Stevia + Stress). One-way ANOVA* was performed to identify differences between subgroups and two-way ANOVA ${ }^{\star *}$ to compare the stressed and unstressed groups. Statistical significance was considered at $p<0.05$

\subsection{Discussion}

\subsubsection{Glucose concentration increased with stress and non-nutritive sweeteners, resulting in changes in body weight}

In unstressed animals, the glucose concentration was elevated in the Sucl subgroup after 6 weeks of treatment, as opposed to a decrease in the St subgroup. In the stressed group, on the other hand, the glucose concentration was relatively high in all subgroups, particularly in Sucl $+S$ (Fig. 1). One explanation for this behavior is that sympathetic nervous system activation produces acute hyperglycemia that helps meet the energetic demands of a stressor, such as increased glucose stress [33], elicits glucocorticoid hypersecretion, which causes hyperinsulinemia, hypersecretion of steroid hormones, visceral adiposity, muscle loss, hypertension, glucose intolerance, dyslipidemia and metabolic syndrome, all of which antagonize insulin and increase blood glucose, independently of their effects on insulin [34]. Hyperglycemia as a response to stress [35] is generated by a reduction of tissue sensitivity to insulin concentration, which means the stress model presently employed was adequate. 


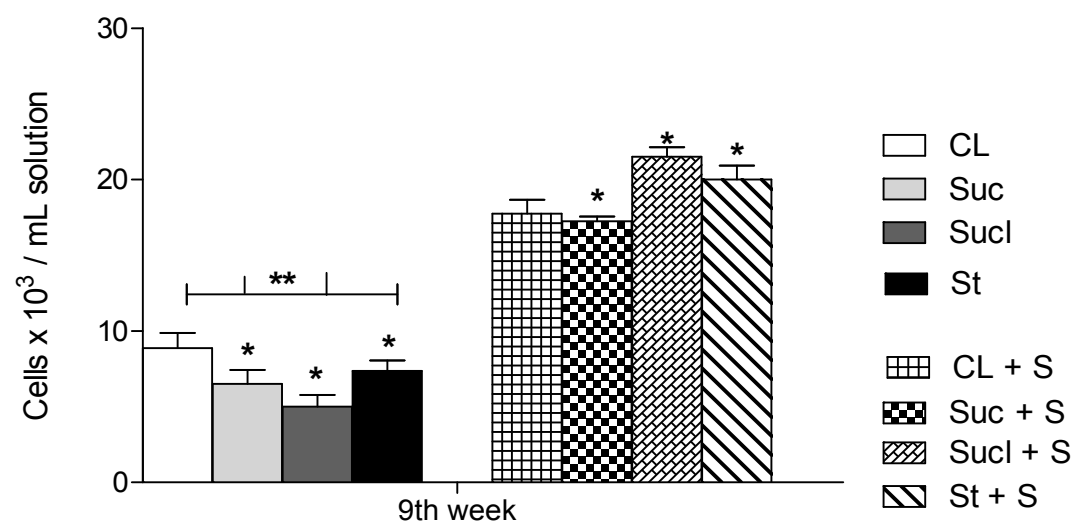

Fig. 2. Number of peripheral blood lymphocytes of CD1 mice, stressed and unstressed, with administration of sweeteners for 6 weeks

The percentage of lymphocytes was increased in all stressed subgroups, particularly in the subgroups of Sucralose and Stevia, but decreased in the unstressed subgroups.

Values represent the mean $\pm S D$ of each group: CL (Control), Suc (Sucrose), Sucl (Sucralose), St (Stevia), CL + $S$ (Control + Stress), Suc + S (Sucrose + Stress), Sucl + S (Sucralose + Stress), and St + S (Stevia + Stress).

One-way ANOVA* was performed to determine differences between subgroups and two-way ANOVA ${ }^{* *}$ to compare the stressed and unstressed groups. Statistical significance was considered at $p<0.05$

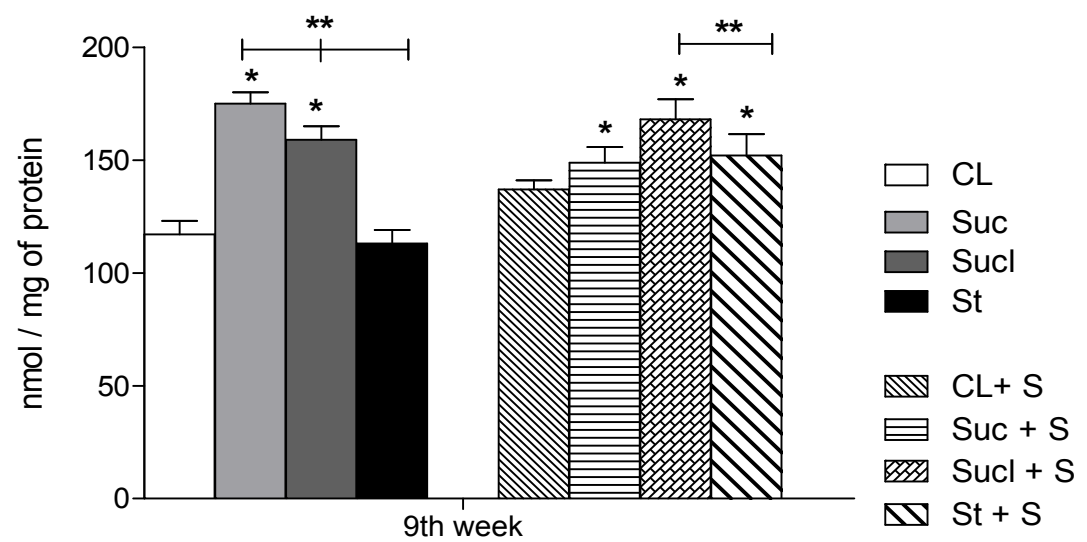

Fig. 3. Concentration of carbonyl proteins in lymphocytes of CD1 mice, stressed and unstressed, with administration of sweeteners for 6 weeks

Sucrose and Sucralose increase the concentration of carbonylated proteins in both groups (stressed and unstressed). The consumption of all sweeteners added to the presence of stress, increases in a greater proportion the concentration of the carbonylated proteins.

Values represent the mean $\pm S D$ of each group: CL (Control), Suc (Sucrose), Sucl (Sucralose), St (Stevia), CL + $S$ (Control + Stress), Suc + S (Sucrose + Stress), Sucl + S (Sucralose + Stress), and St + S (Stevia + Stress). One-way ANOVA* was performed to identify differences between subgroups and two-way ANOVA ${ }^{* *}$ to compare the stressed and unstressed groups. Statistical significance was considered at $p<0.05$

Several variations of a chronic low-grade stress protocol (CLGS) are used to research stressinduced anxiety and depression in rodents. The behavioral changes prompted by unpredictable physical and psychological stressors can be quantified by measuring modifications in body weight [36]. In the current study, the unstressed animals did not undergo a change in body weight or BMI, even when consuming sweeteners. Contrarily, weight and BMI decreased in the stevia + stress subgroup, but increased in the sucralose + stress animals. Abo Elnaga et al. [37] reported that the administration of stevia reduced food intake in a dose dependent 
manner, with a reduction in body weight found in all study groups regardless of the dose, after 12 weeks of treatment [37]. Non-nutritive sweeteners are not physiologically inert, as they are able to affect energy balance, some metabolic functions, taste perception, hormonal secretion, and cognitive processes such as memory and reward learning [38]. On the other hand, stress may modify food intake as well as weight and $\mathrm{BMI}$, conditioning the increase produced by non-nutritive sweeteners. It is also possible that weight changes are due to the effects of stress, and not to the sweetener. In the case of the combination of stress and sucralose, there was an overall weight increase of the mice [38].

Chronic physiological stress has been associated with a number of psychological, neurodegenerative, cardiovascular and immunological diseases. This emerging risk factor could possibly lead to excessive food intake, and thus may result in the development of abdominal fat and obesity, [39]. In mice, a highfat or high-carbohydrate diet combined with chronic stress foments visceral adiposity and metabolic syndrome, even more than the boost in these parameters found in their non-stressed counterparts. Physiological stress has been linked to weight loss as well as weight gain and energy homeostasis alterations. It is still not clear why stress contributes to metabolic dysfunction under some circumstances and not others [40].

Kubera et al. [41] have demonstrated that cortisol elicits greater effects of neuropeptide Y (NPY), which acts on visceral adipocytes and induces to hyperplasia, favoring in this manner an increase in abdominal fat and BMI. Non-nutritive sweeteners are correlated with higher BMI, suggesting that they can promote weight gain [42]. The role of non-nutritive sweeteners in weight control and health is still controversial [43]. According to the current results, chronic stress together with prolonged non-nutritive sweetener intake, specifically sucralose, may cause a weight gain in rodents.

\subsubsection{Sucralose administration reduced food intake}

For the stressed and unstressed groups, sucralose diminished food intake but stevia led to a rise in this parameter during the 6 weeks of treatment. Pepino et al. [44] suggest that non-nutritive sweeteners foster metabolic deregulation, weakening the ability of sweetness to predict energy and evoke autonomous and endocrine acquired responses that prepare the gut for the optimal processing of food ingested. Such is the case of the interaction between the cephalic response and intestinal microbiota to trigger glucose intolerance [44]. Non-nutritive sweeteners interact with sweetness receptors expressed along the digestive tract, which participate in glucose absorption and initiate insulin secretion. This activity has been described in reports on the effect of non-nutritive sweeteners from beverages [44]. In another work, Ross et al. described a significant weight gain without changes in BMI, as well as development of obesity, insulin resistance and steatosis in mice injected with epinephrine to produce stress and mice with a high level of sucrose and lard in the diet for 5 days. Additionally, they found that such a diet intensifies the ability of epinephrine to elevate blood glucose concentrations, particularly in rats, which become obese under these conditions [33]. In the present study, the administration of sucrose and stevia decreased body weight in mice subjected to stress, while augmenting food intake and blood glucose. On the other hand, sucralose administration plus stress led to increased weight and blood glucose levels, with reduced food intake. Moreover, unstressed mice consumed less water when given sucralose. Contrarily, the stressed group showed higher water intake with the administration of sucralose and stevia, most probably caused by the stress factor and an increase in glycemia.

In summary, the interaction of stress with a 6week administration of sucralose in the early stages of life herein affected morphometric parameters and raised the blood glucose concentration to an even greater extent than that found with sucrose. More consumption of sucralose, and greater food intake, evidencing that this sweetener stimulated the appetite. Animals administered sucralose had a significantly lower weight in the presence versus absence of stress. The animals under stress and given stevia, contrarily, exhibited relatively high food intake but a reduction in body weight and BMl together with no change in blood glucose concentration. It is possible that stevia improves the metabolic state of an individual.

\subsubsection{Sucralose increased the percentage of blood lymphocytes and the concentration of carbonylated proteins}

The percentage of blood lymphocytes declined in unstressed animals given Suc or Sucl, a change 
associated with an elevated concentration of carbonylated proteins. Orally administered sucralose is rapidly absorbed, with a variation between species (mice, rats, rabbits, dogs and humans) in overall absorbance of the dose, ranging from 18 to $48 \%$ (approximately $30 \%$ in mice). Several organs may be affected by the consumption of high doses of sucralose, even though the majority of this substance is excreted through the urine without change [10]. Thus, it is necessary to evaluate the effects of a prolonged use of sucralose, especially since nowadays the population tends to consume more products with this sweetener in order to reduce energy intake.

In the stressed mice, there was a relatively high percentage of blood lymphocytes and carbonylated proteins in all groups (Suc $+\mathrm{S}$, Sucl $+S$ and $S t+S$ ), probably attributable to stress rather than the sweeteners. Chronic physiological stress is a risk factor for several diseases, such as metabolic syndrome [45] and obesity [46]. With stress, an increase in carbonylated protein concentration and hyperglycemia may contribute to a decline in lymphocytes, thus prompting a state of oxidative stress.

Ceriello \& Motz observed that the reduction of hyperglycemia can lower oxidative stress [47]. Whereas a decrease in physiological stress likely improves control of glycemia in patients with diabetes [48], the presence of stress stimulates food intake [49] and activates certain mechanisms in adipose tissue that lead to greater fat accumulation [50]. The latter effect has been reported in mice exposed to chronic stress and fed diets high in sugar and fat, leading these animals to develop visceral adiposity and metabolic syndrome considerably faster than their non-stressed counterparts [50]. Excessive consumption of sugar tends to increase energy substrates, promoting ROS production by the mitochondria and causing oxidative stress [51]. Although sucralose has no energy, it does augment food intake and possibly induces greater energy uptake, which could elicit a rise in carbonylation of proteins. An elevated level of oxidative stress is linked to obesity, diabetes [52], cardiovascular mortality [53], fatty liver and insulin resistance $[47,54]$.

As an indicator of oxidative stress, we measured the concentration of carbonylated proteins, which are resistant to degradation and represent irreversible damage leading to the loss of protein function. This parameter is considered a measurement of generalized oxidative damage begotten by ageing. It is not yet clear whether these proteins are produced because of disease or represent tissue damage resulting from disease [55].

The present administration of non-nutritive sweeteners (particularly sucralose) caused hyperglycemia, altered food intake, and increased carbonylated protein concentrations in the blood of both stressed and unstressed healthy young mice. Regarding stevia, no change existed in glucose level, weight gain, BMI or carbonylated protein concentration, even though the percentage of lymphocytes and food intake rose. These data suggest that the presence of carbonylated proteins prompts oxidative stress before the development of clinical disease.

According to Sehar et al., the administration of steviosides augments $\mathrm{T}$ and $\mathrm{B}$ lymphocyte proliferative responses to mitogens in a dose dependent manner [19]. An opposite response was observed herein, since the administration of stevia in the unstressed group did not modify the percentage of lymphocytes nor the concentration of carbonylated proteins, the latter of which remained at a low level. In the stressed group, a high level of the percentage of lymphocytes and the concentration of carbonylated proteins was found in all groups. Therefore, the stimulatory effect can be attributed to stress, not directly to steviosides. It is possible that the lack of increase in the concentration of carbonylated proteins in the group given stevia was due to the additional benefits provided by this particular sweetener, including reduced hyperglycemia, hypertension, inflammation, tumorigenesis, diarrhea and diuresis as well as modulation of the immune system. Some components of the plant eliminate ROS. Moreover, pharmacological benefits have been reported for extracts of stevia leaves. These data imply that the extracts from the leaves of E. Rebaudiana may be employed not only as a non-nutritive sweetener, but also as a natural antioxidant [56]. The administration of stevia leaves or steviosides decreases the plasma glucose level of diabetic rats and reduces thiobarbituric acid reactive species (TBARS) in a dose-dependent manner [37]. The use of stevia is currently increasing as a non-nutritive sweetener, while its antioxidant activity is still under investigation [57].

There are no studies associating the intake of non-nutritive sweeteners with the presence of 
physiological stress or oxidative stress in blood lymphocytes. Chronic stress has been related to the presence of oxidative stress in liver, kidney, heart, lungs and brain [27], but there are not studies especially in lymphocytes. The majority of studies focus on evaluating carbonylated protein concentrations in human pathologic states. The results of these studies suggest that the increase in oxidative stress may be not really due to complications of these diseases but may be contributors to their development as they all are at advanced stages of inflammation. [28]. Studies evaluating the effect of non-nutritive sweeteners on oxidative stress in healthy subjects are scarce.

The present study examined the impact of nonnutritive sweeteners on oxidative stress in healthy subjects. It is still not clear whether excessive ROS levels in pathologies such as diabetes mellitus type 2 is a causative factor or a result of the development of the disease. It is possible that ROS is responsible for complications associated with hyperglycemia in the late stages of the disease, but it has not yet been elucidated whether ROS are already present in the early stages of the disease [58].

In the current contribution, we administered the sweeteners to healthy mice, controlling the factors of dose and age. We observed that the chronicity of exposure to these substances, whether with or without stress, caused hyperglycemia and an elevated level of carbonylated proteins. In the long run, this effect could be detrimental to the organism because of triggering cellular dysfunction and tissue damage [28]. Even though the literature on the biological consequences of non-nutritive sweeteners is still controversial, particularly in humans, the evidence suggests that they are not physiological inert and may affect nutrition and metabolism through a variety of peripheral and central mechanisms [38]. The way in which they function within the gastrointestinal, neuronal and endocrine systems to regulate energy balance is not yet well understood, particularly in regard to sucralose and stevia. Further research is needed on these questions.

\section{CONCLUSION}

Stress with the prolonged administration of sucralose modified the number of lymphocytes and increased the concentration of carbonylated proteins. Contrarily, stevia increased the number of cells and reduced the production of carbonylated proteins. Apparently the sweeteners consumption influences the food intake. Chronic consumption of sucralose in the early stages of life in both stressed and unstressed animals reduced food intake, modified the percentage of lymphocytes, and increased the concentration of glucose and carbonylated proteins.

\section{ETHICAL APPROVAL}

The project from which this article derives was reviewed and approved by the Research Ethics Committee of the Faculty of Medicine, Universidad Autónoma del Estado de México. Animal care and experimental procedures were carried out in accordance with the standards of the International Regulation for the Use of Laboratory Animals, the norms of the Universidad Autónoma del Estado de México, and the guidelines of the Mexican Secretary of Health for the production and Care of Laboratory Animals (NOM-062-ZOO-1999 Ministry of Agriculture, Mexico City, Mexico).

\section{COMPETING INTERESTS}

Authors have declared that no competing interests exist.

\section{REFERENCES}

1. Fernstrom JD, Navia JL. Workshop summary. J Nutr. 2012;1170-2.

2. Ifland JR, Preuss HG, Marcus MT, Rourke KM, Taylor WC, Burau K, et al. Refined food addiction: A classic substance use disorder. Med Hypotheses. 2009;72(5): 518-26.

3. Gulati S, Misra A. Sugar intake, obesity, and diabetes in India. Nutrients. 2014;6(12):5955-74.

4. Garcia-Almeida JM, Casado Fdez GM, Garcia Aleman J. A current and global review of sweeteners. Regulatory aspects. Nutr Hosp. 2013;28(Suppl 4):17-31.

Available:https://www.ncbi.nlm.nih.gov/pub $\mathrm{med} / 23834089$

5. Schiffman SS, Rother KI. Sucralose, A synthetic organochlorine sweetener: Overview of biological issues. J Toxicol Environ Heal Part B. 2013;16(7):399-451.

6. Chattopadhyay S, Raychaudhuri U, Chakraborty R. Artificial sweeteners - a review. J Food Sci Technol. 2014;51(4): 611-21. 
7. Ferrazzano GF, Cantile T, Alcidi B, Coda $M$, Ingenito A, Zarrelli A. Is Stevia rebaudiana Bertoni a non cariogenic sweetener? A review. Molecules. 2015;21(1):E38.

Available:https://www.ncbi.nlm.nih.gov/pub $\mathrm{med} / 26712732$

8. Sun SZ, Empie MW. Fructose metabolism in humans - what isotopic tracer studies tell us. Nutr Metab. 2012;9(1):89.

9. Tasevska N. Urinary sugars-A biomarker of total sugars intake. Nutrients. 2015;7(7): 5816-33.

10. AIDeeb OA, Mahgoub $\mathrm{H}$, Foda $\mathrm{NH}$. Sucralose. Profiles of Drug Subst, Excip Relat Methodol. 2013;38:423-62.

Available:https://www.ncbi.nlm.nih.gov/pub $\mathrm{med} / 23668410$

11. Shannon M, Rehfeld A, Frizzell C, Livingstone C, McGonagle C, Skakkebaek $\mathrm{NE}$, et al. In vitro bioassay investigations of the endocrine disrupting potential of steviol glycosides and their metabolite steviol, components of the natural sweetener Stevia. Mol Cell Endocrinol. 2016;427:6572.

12. Guideline: Sugars intake for adults and children. Geneva: World Health Organization; 2015.

ISBN: 978-92-4-154902-8.

(Consulted: April 9, 2017)

Available:http://www.who.int/nutrition/publi cations/guidelines/sugars intake/en/

13. Schiffman SS, Abou-Donia MB. Sucralose revisited: Rebuttal of two papers about Splenda safety. Regul Toxicol Pharmacol. 2012;63(3):505-8.

14. Suez J, Korem T, Zeevi D, ZilbermanSchapira G, Thaiss CA, Maza O, et al. Artificial sweeteners induce glucose intolerance by altering the gut microbiota. Nature. 2014;514(7521):181-6.

Available:https://www.ncbi.nlm.nih.gov/pub $\mathrm{med} / 25231862$

15. Barriocanal LA, Palacios M, Benitez G, Benitez S, Jimenez JT, Jimenez N, et al. Apparent lack of pharmacological effect of steviol glycosides used as sweeteners in humans. A pilot study of repeated exposures in some normotensive and hypotensive individuals and in Type 1 and Type 2 diabetics. Regul Toxicol Pharmacol. 2008;51(1):37-41.

16. Anton SD, Martin CK, Han H, Coulon S, Cefalu WT, Geiselman P, Williamson DA. Effects of stevia, aspartame, and sucrose on food intake, satiety, and postprandial glucose and insulin levels. Appetite. 2010;55(1):37-43.

17. Bray GA. Energy and fructose from beverages sweetened with sugar or highfructose corn syrup pose a health risk for some people. Adv Nutr. 2013;4(2):220-5.

18. Rahiman $\mathrm{F}$, Pool EJ. The in vitro effects of artificial and natural sweeteners on the immune system using whole blood culture assays. J Immunoass Immunochem. 2014;35(1):26-36.

19. Sehar I, Kaul A, Bani S, Pal HC, Saxena AK. Immune up regulatory response of a non-caloric natural sweetener, stevioside. Chem Biol Interact. 2008;173(2):115-21.

20. Chrousos GP, Gold PW. The concepts of stress and stress system disorders. Overview of physical and behavioral homeostasis. JAMA. 1992;267(9):124452.

21. McEwen BS. Physiology and neurobiology of stress and adaptation: Central role of the brain. Physiol Rev. 2007;87(3):873904.

22. Kapoor A, Dunn E, Kostaki A, Andrews $\mathrm{MH}$, Matthews SG. Fetal programming of hypothalamo-pituitary-adrenal function: Prenatal stress and glucocorticoids. J Physiol. 2006;572(1):31-44.

23. Cyr NE, Romero LM. Identifying hormonal habituation in field studies of stress. Gen Comp Endocrinol. 2009;161(3):295-303.

24. Zimatkin SM, Buben Al. Ethanol oxidation in the living brain. Alcohol Alcohol. 2007;42(6):529-32.

25. Poljšak $B$, Fink R. The protective role of antioxidants in the defence against ROS/RNS-mediated environmental pollution. Oxid Med Cell Longev. 2014;2014:671539.

26. Kelly GS. Nutritional and botanical interventions to assist with the adaptation to stress. Altern Med Rev. 1999;4(4):24965.

Available:https://www.ncbi.nlm.nih.gov/pub med/10468649

27. López-López AL, Jaime HB, Escobar Villanueva $\mathrm{M}$ del $\mathrm{C}$, Padilla $\mathrm{MB}$, Palacios GV, Aguilar FJ. Chronic unpredictable mild stress generates oxidative stress and systemic inflammation in rats. Physiol Behav. 2016;161:15-23.

28. Dalle-Donne I, Aldini G, Carini M, Colombo R, Rossi R, Milzani A. Protein carbonylation, cellular dysfunction, and disease progression. J Cell Mol Med. 2006;10(2):389-406. 
29. Stadtman ER, Berlett BS. Reactive oxygen.mediated protein oxidation in aging and disease. Chem Res Toxicol. 1997;10(5):485-94.

30. Diniz YS, Burneiko RM, Seiva FR, Almeida FQ, Galhardi CM, Filho JL, Mani F, Novelli EL. Diet compounds, glycemic index and obesity-related cardiac effects. Int $\mathrm{J}$ Cardiol. 2008;124(1):92-9.

31. Novelli EL, Diniz YS, Galhardi CM, Ebaid $G M$, Rodrigues HG, Mani $F$, et al. Anthropometrical parameters and markers of obesity in rats. Lab Anim. 2007;41(1): 111-9.

32. Reznick AZ, Packer L. Oxidative damage to proteins: Spectrophotometric method for carbonyl assay. Methods Enzymol. 1994;233:357-63.

33. Ross AP, Darling JN, Parent MB. Excess intake of fat and sugar potentiates epinephrine-induced hyperglycemia in male rats. J Diabetes Complications. 2015;29(3):329-37.

34. Fernando HA, Chin HF, Ton SH, Abdul Kadir K. Stress and its effects on glucose metabolism and $11 \beta-H S D$ activities in rats fed on a combination of high-fat and highsucrose diet with glycyrrhizic acid. J Diabetes Res. 2013;2013:190395. Epub 2013 Mar 18.

Available:https://www.ncbi.nlm.nih.gov/pm c/articles/PMC3647599/

35. Gesto M, Otero-Rodiño C, López-Patiño MA, Míguez JM, Soengas JL, CondeSieira M. Is plasma cortisol response to stress in rainbow trout regulated by catecholamine-induced hyperglycemia? Gen Comp Endocrinol. 2014;205:207-17.

36. Monteiro S, Roque S, de Sá-Calcada D, Sousa N, Correia-Neves M, Cerqueira JJ. An efficient chronic unpredictable stress protocol to induce stress-related responses in C57BL/6 mice. Front Psychiatry. 2015; 6:6.

Available:https://www.ncbi.nlm.nih.gov/pm c/articles/PMC4313595/

37. Abo Elnaga NIE, Massoud MI, Yousef MI, Mohamed HHA. Effect of stevia sweetener consumption as non-caloric sweetening on body weight gain and biochemical's parameters in overweight female rats. Ann Agric Sci. 2016;61(1):155-63.

38. Burke MV, Small DM. Physiological mechanisms by which non-nutritive sweeteners may impact body weight and metabolism. Physiol Behav. 2015; 152(Pt B):381-8.
39. Ha HY, Kim KS, Yeom YI, Lee JK, Han PL. Chronic restraint stress massively alters the expression of genes important for lipid metabolism and detoxification in liver. Toxicol Lett. 2003;146(1):49-63.

40. Aschbacher $\mathrm{K}$, Kornfeld $\mathrm{S}$, Picard $\mathrm{M}$, Puterman E, Havel PJ, Stanhope K, et al. Chronic stress increases vulnerability to diet-related abdominal fat, oxidative stress, and metabolic risk. Psychoneuroendocrinology. 2014;46:1422.

41. Kubera B, Hubold C, Wischnath H, Zug S, Peters A. Rise of ketone bodies with psychosocial stress in normal weight men. Psychoneuroendocrinology. 2014;45:43-8.

42. Yang Q. Gain weight by "going diet?" Artificial sweeteners and the neurobiology of sugar cravings: Neuroscience 2010. Yale J Biol Med. 2010;83(2):101-108.

43. Tandel KR. Sugar substitutes: Health controversy over perceived benefits. J Pharmacol Pharmacother. 2011;2(4):23643.

44. Pepino MY. Metabolic effects of nonnutritive sweeteners. Physiol Behav. 2015;152(Pt B):450-5.

45. Pyykkönen AJ, Räikkönen $\mathrm{K}$, Tuomi $\mathrm{T}$, Eriksson JG, Groop L, Isomaa B. Stressful life events and the metabolic syndrome: The prevalence, prediction and prevention of diabetes (PPP) -Botnia study. Diabetes Care. 2010;33(2):378-84.

46. Brunner EJ, Chandola T, Marmot MG. Prospective effect of job strain on general and central obesity in the Whitehall II study. Am J Epidemiol. 2007;165(7):82837.

47. Ceriello A, Motz E. Is oxidative stress the pathogenic mechanism underlying insulin resistance, diabetes, and cardiovascular disease? The Common Soil Hypothesis Revisited. Arterioscler Thromb Vasc Biol. 2004;24(5):816-23.

48. Ismail K, Winkley K, Rabe-Hesketh S. Systematic review and meta-analysis of randomised controlled trials of psychological interventions to improve glycaemic control in patients with type 2 diabetes. Lancet. 2004;363(9421):158997.

49. Epel E, Jimenez S, Brownell K, Stroud L, Stoney C, Niaura R. Are stress eaters at risk for the metabolic syndrome? Ann N Y Acad Sci. 2004;1032:208-10.

50. Kuo LE, Kitlinska JB, Tilan JU, Li L, Baker SB, Johnson MD, et al. Neuropeptide $Y$ 
acts directly in the periphery on fat tissue and mediates stress-induced obesity and metabolic syndrome. Nat Med. 2007;13(7):803-11.

51. Anderson EJ, Lustig ME, Boyle KE, Woodlief TL, Kane DA, Lin C Te, et al. Mitochondrial $\mathrm{H} 2 \mathrm{O} 2$ emission and cellular redox state link excess fat intake to insulin resistance in both rodents and humans. J Clin Invest. 2009;119(3):573-81.

52. Keaney JF, Larson MG, Vasan RS, Wilson PW, Lipinska I, Corey D, et al. Obesity and systemic oxidative stress: Clinical correlates of oxidative stress in the Framingham study. Arterioscler Thromb Vasc Biol. 2003;23(3):434-9.

53. Roest M, Voorbij HA, Van der Schouw YT, Peeters PH, Teerlink T, Scheffer PG. High levels of urinary F2-isoprostanes predict cardiovascular mortality in postmenopausal women. J Clin Lipidol. 2008;2(4):298-303.

54. Hoehn KL, Salmon AB, Hohnen-behrens C, Turner N, Hoy AJ, Maghzal GJ, et al. Insulin resistance is a cellular antioxidant defense mechanism. Proc Natl Acad Sci USA. 2010;106(42):17787-92.

55. Dalle-Donne I, Rossi R, Giustarini D, Milzani A, Colombo R. Protein carbonyl groups as biomarkers of oxidative stress. Clin Chim Acta. 2003;329(1-2):23-38.

56. Álvarez-Robles MJ, López-Orenes A, Ferrer MA, Calderón AA. Methanol elicits the accumulation of bioactive steviol glycosides and phenolics in Stevia rebaudiana shoot cultures. Ind Crops Prod. 2016;87:273-9.

57. Carbonell-Capella JM, Buniowska M, Esteve MJ, Frígola A. Effect of Stevia rebaudiana addition on bioaccessibility of bioactive compounds and antioxidant activity of beverages based on exotic fruits mixed with oat following simulated human digestion. Food Chem. 2015;184:122-30.

58. Anderson EJ, Lustig ME, Boyle KE, Woodlief TL, Kane DA, Lin CT, et al. Mitochondrial $\mathrm{H} 2 \mathrm{O} 2$ emission and cellular redox state link excess fat intake to insulin resistance in both rodents and humans. J Clin Invest. 2009;119(3):573-81.

(c) 2017 García-Iniesta et al.; This is an Open Access article distributed under the terms of the Creative Commons Attribution License (http://creativecommons.org/licenses/by/4.0), which permits unrestricted use, distribution, and reproduction in any medium, provided the original work is properly cited. 